\title{
Risk of tuberculosis during infliximab therapy for inflammatory bowel disease, rheumatoid arthritis, and spondyloarthropathy: A meta-analysis
}

\author{
QIANG WANG $^{1^{*}},{\text { ZHENZHEN } \mathrm{WEN}^{2 *} \text { and QIAN CAO }}^{2}$ \\ ${ }^{1}$ Department of Hepatobiliary and Pancreatic Surgery, Zhejiang Provincial People's Hospital, Hangzhou, Zhejiang 310014; \\ ${ }^{2}$ Department of Gastroenterology, Sir Run Run Shaw Hospital, School of Medicine, \\ Zhejiang University, Hangzhou, Zhejiang 310016, P.R. China
}

Received May 12, 2015; Accepted June 27, 2016

DOI: $10.3892 /$ etm.2016.3548

\begin{abstract}
Infliximab is a promising drug with good outcomes demonstrated for diseases such as inflammatory bowel disease (IBD), rheumatoid arthritis (RA) and spondyloarthropathy (SpA). However, treatment with this drug may increase the risk of tuberculosis infection. The aim of the present study was to investigate infliximab-associated tuberculosis infection. Literature searches in PubMed, MEDLINE and EMBASE databases were performed. Randomized controlled trials with $>95 \%$ of the patients $>18$ years-old were included. Meta-analysis was performed to investigate the incidence of tuberculosis infection after infliximab infusion. A total of 24 RCTs were included in the present meta-analysis. In total, $21(0.51 \%)$ tuberculosis infections were detected among 4,111 patients administered infliximab therapy, compared with $0(0 \%)$ among 2,229 patients assigned to the placebo group. Pooled odds ratio (OR) of developing tuberculosis infection was significantly higher with infliximab therapy than with placebo [2.86; 95\% confidence interval (CI), 1.09-7.52]. The OR of tuberculosis infection was 3.93 (95\% CI, 0.91-16.91) in RA, 2.46 (95\% CI, 0.38-15.92) in SpA and 1.66 (95\% CI, 0.26-10.57) in IBD. Rates of tuberculosis infection with infliximab therapy in RA, SpA and IBD were $0.70,0.22$ and $0.52 \%$, respectively. Compared with placebo, infliximab therapy may increase the risk of developing tuberculosis. However, the ORs for the risk of infliximab-associated tuberculosis were not demonstrated
\end{abstract}

Correspondence to: Professor Qian Cao, Department of Gastroenterology, Sir Run Run Shaw Hospital, School of Medicine, Zhejiang University, 3 East Qing Chun Road, Hangzhou, Zhejiang 310016, P.R. China

E-mail: 82281148@qq.com

*Contributed equally

Key words: tuberculosis infection, infliximab, inflammatory bowel disease, rheumatoid arthritis, spondyloarthropathy, meta-analysis to be significant in IBD, RA and SpA; therefore, these findings should be interpreted with caution. The risk of developing tuberculosis demonstrates the importance of the prevention and management of tuberculosis infection with infliximab therapy.

\section{Introduction}

Infliximab is a genetically constructed immunoglobulin (Ig)G1 murine-human chimeric monoclonal antibody that binds the soluble subunit and the membrane-bound precursor of tumor necrosis factor- $\alpha$ (TNF- $\alpha)$. Consequently, it helps to decrease the biological activity of $\operatorname{TNF}-\alpha(1,2)$. Neutralization of TNF- $\alpha$ has been suggested as a therapeutic strategy for patients with inflammatory bowel disease (IBD), rheumatoid arthritis (RA), spondyloarthropathy (SpA) and various other chronic inflammatory conditions (3-5). IBD, $\mathrm{RA}$, and $\mathrm{SpA}$ are common chronic inflammatory conditions, characterized by episodes of remission and relapse, which have a major impact on the patients' physical, emotional and social well-being. TNF- $\alpha$ cytokine, which is expressed by activated macrophages, has been implicated in the pathogenesis of IBD, RA and SpA (6-8). Infliximab has been widely used to treat patients who failed to respond to other anti-inflammatory agents since FDA approval was attained in 1998. The advent of infliximab has dramatically improved the quality of life and prognosis of these patients.

Multicenter randomized clinical trials (RCTs) have been conducted to evaluate the efficacy and safety of infliximab throughout the past decade. These RCTs demonstrated that infliximab is an effective therapy for the treatment of various inflammatory diseases (9-12). However, the safety of infliximab remains a major concern to physicians and patients, including its short- and long-term side effects, which have limited its clinical use. Although the side effects are uncommon, they may be serious and potentially life-threatening. The most common side effects include infection, infusion reactions, tumor and lupus-like syndrome. Miscellaneous types of infections, such as bacterial, mycobacteria, invasive fungal, viral and parasitic infections have been observed since the approval of infliximab (13). 
In animal models, TNF- $\alpha$ has been demonstrated to have a central role in the host response against tuberculosis, including granuloma formation and the containment of disease $(14,15)$. Notably, antibodies against TNF- $\alpha$ induced reactivation of tuberculosis in a mouse model of latent infection (16). The role of TNF- $\alpha$ in the human immune response to tuberculosis remains unclear, and the effect on the tuberculosis infection of infliximab requires clarification. Previous large retrospective reviews of infliximab-induced tuberculosis have shown that the frequency of tuberculosis following infliximab therapy was elevated, as compared with other opportunistic infections (17). In addition, the rate of reported cases of tuberculosis treated with infliximab is higher than the background rate of tuberculosis in patients with rheumatoid arthritis (18-20). However, the findings of previous RCTs that examined the association between infliximab and tuberculosis infection risk were inconsistent. The aim of present study was to analyze the findings of RCTs that investigated infliximab, with an emphasis on tuberculosis infection risk.

\section{Materials and methods}

Search strategy and study selection. To perform this review, we conducted a structured search in PubMed (ncbi.nlm.nih.gov/pubmed), MEDLINE (http://webofknowledge.com/medline) and EMBASE (http://www.embase. com) databases up to May 2014 using the following search terms: ('inflammatory bowel disease' or 'Crohn's disease' or 'ulcerative colitis' or 'rheumatoid arthritis' or 'spondyloarthropathy') and ('remicade' or 'infliximab' or 'monoclonal antibody cA2') and ('tuberculosis' or 'mycobacterial infections'). References from the articles that met the eligibility criteria were also examined and evaluated, and were selected for this review if they also met the criteria. Only articles published in English were included. Titles and abstracts of articles identified by the initial search were first evaluated by investigators for appropriateness to the study question, and full papers of potential eligible studies were subsequently obtained and reviewed in detail. The present meta-analysis was designed, analyzed and reported according to the PRISMA statement (21).

Criteria for the inclusion of an article in the present meta-analysis were as follows: (i) Randomized controlled trials; (ii) $>95 \%$ of the patients are aged $>18$ years; and (iii) compared infliximab with or without concomitant immunomodulators therapy with placebo. Furthermore, for inclusion, studies were required to be independent from other studies in order to avoid giving double weight to estimates derived from the same trial, and to have sufficient information to allow adequate estimation of the relative risk (RR)/odds ratio (OR) and $95 \%$ confidence intervals (CIs).

Studies were excluded if: (i) They were a review, lecture, comment or research that cannot be extracted with statistical data; or (ii) they included patients that were pregnant, hypersensitive to infliximab, exhibited systemic disease, or were given biological treatment previously.

Outcome assessment. The primary outcome was the occurrence of tuberculosis infection with infliximab, compared with placebo. The secondary outcome was mortality due to tuberculosis infection.

Data extraction. Two investigators individually evaluated all relevant articles identified by the literature search using pre-defined eligibility forms. Any discrepancies were resolved by discussion. The following information was obtained from each study: First author, year of publication, geographical region, disease type, sample size during the study, dosage of infliximab, duration of therapy, combination therapy (if any), number of individuals who experienced tuberculosis infection, tuberculosis manifestation, and prognosis of tuberculosis. Data were extracted as intention-to-treat analyses, wherever trial reporting facilitated this.

Quality evaluation. Jadad scoring was applied to assess the methodological quality of included trials, which judges the descriptions of randomization, double blinding, and subject withdrawal in the included trials (22). The quality scale ranges from 0 to 5 points with a low-quality report scoring $\leq 2$ and a high-quality report scoring $\geq 3$ (23).

Statistical analysis. Statistical heterogeneity between the studies was assessed using $\chi^{2}$ test and $I^{2}$, which assumes the presence of heterogeneity at $\mathrm{P}<0.10$ and/or $I^{2}>50 \%$. A fixed effects model was used when the heterogeneity test demonstrated a P-value of $>0.10$ and a $I^{2}$ of $<50 \%$; otherwise, a random-effects model was used. Subgroup analyses were performed according to disease type, sample size, study quality, duration of therapy, whether patients in both infliximab and placebo arms were exposed to immunosuppressants and whether patients enrolled in infliximab and placebo arms were screened for tuberculosis. We compared individual ORs between these analyses using the Cochran $Q$ statistic tool.

Funnel plot graph, and Begg and Egger tests were performed to evaluate publication bias. All analyses were conducted using the Revman 5.0 (Nordic Cochrane Centre, Copenhagen, Denmark) and Stata software (11.0; StataCorp LP, College Station, TX, USA). P<0.05 was considered to indicate a statistically significant difference.

\section{Results}

Literature search and characteristics of the included studies. The present search strategy identified 6,892 articles, 6,553 of which were excluded after the title and abstract were reviewed. For the remaining 339 articles, 316 articles were excluded due to duplication $(n=54)$, not being an RCTs $(n=127)$, a lack of placebo $(n=67)$, no outcome of interest $(n=49)$, and no data on tuberculosis $(n=19)$. Finally, 23 articles were included in the present meta-analysis, reporting on 24 respective RCTs. Of these, 8 studies studied infliximab-associated tuberculosis incidence in IBD (24-32), one of which reported two separate trials (29), 7 trials studied infliximab-associated tuberculosis incidence rates in RA (33-39), and 8 trials studied infliximab-associated tuberculosis incidence in SpA (40-47). A flow diagram of the selection process for the inclusion of studies in the present meta-analysis is shown in Fig. 1.

Duration of follow-up ranged between 12 and 54 weeks. The characteristics of the 24 trials are presented in 


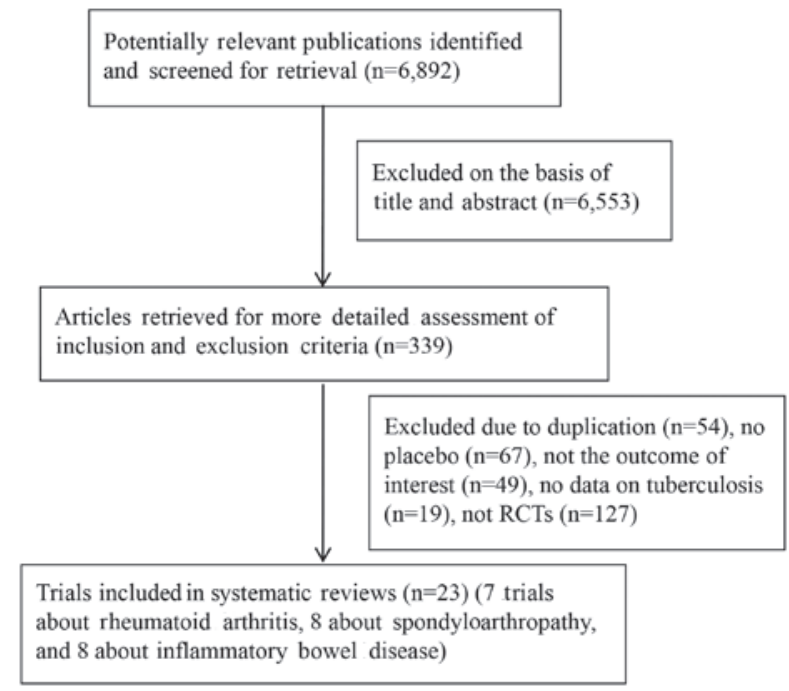

Figure 1. Flowchart of study selection process. RCT, randomized controlled trial.

Tables I and II, including the year the studies were conducted, number of patients treated, dose of infliximab administered, incidence of tuberculosis infection, tuberculosis manifestation, prognosis of tuberculosis and tuberculosis screening test prior to therapy.

Rates of tuberculosis infection in IBD, RA and SpA. Table III presents the rates of tuberculosis infection within each trial arm in each inflammatory disease assessed. Rates of tuberculosis infection with infliximab therapy were $0.70,0.22$ and $0.52 \%$, respectively; whereas the rates of tuberculosis infection with placebo were consistently $0 \%$, in RA, SpA and IBD. The rates of tuberculosis infection with infliximab therapy in IBD, RA and SpA were all higher than the rates with placebo.

Overall risk of tuberculosis infection with infliximab therapy vs. placebo in IBD, RA and SpA. The 24 trials examined in the present meta-analysis contain a total of 6,340 patients with IBD, RA and SpA. Of these, 4,111 (64.8\%) patients were randomized to receive infliximab therapy, and 2,229 (35.2\%) patients were administered a placebo. In total, there were $21(0.51 \%)$ patients assigned to infliximab therapy who developed tuberculosis infection, as compared with $0(0 \%)$ among patients allocated to placebo therapy. The pooled OR of developing tuberculosis infection was significantly increased with infliximab therapy, as compared with the placebo [2.86; 95\% CI, 1.09-7.52] (Fig. 2), with no statistically significant heterogeneity detected between the studies $\left(I^{2}=0 \% ; \mathrm{P}=0.99\right)$. However, in each disease subgroup, the trends were not statistically significant. The OR of tuberculosis infection with infliximab therapy was 3.93 (95\% CI, 0.91-16.91) in RA, 2.46 (95\% CI, 0.38-15.92) in SpA, and 1.66 (95\% CI, 0.26-10.57) in IBD. The difference among these subgroups was not statistically significant (Cochran $Q=0.53 ; \mathrm{P}=0.77$ ) (Fig. 2). The findings demonstrate that infliximab therapy may increase the risk of developing tuberculosis compared with that for treatment with placebo.
Meta-analysis of tuberculosis infection with infliximab therapy vs. placebo in each subgroup. Subgroup analyses were performed (Table IV). The OR of tuberculosis infection with infliximab therapy was elevated in trials with $\geq 50$ weeks of treatment (3.00;95\% CI,0.97-9.29), as compared with those with a duration of $<50$ weeks $(2.46 ; 95 \%$ CI, 0.38-15.92); however, there was no statistically significance (Cochran $Q=0.03$; $\mathrm{P}=0.86$ ). Furthermore, the $\mathrm{OR}$ was also increased in the larger sample studies $(2.94 ; 95 \%$ CI, 0.87-9.94), as compared with the smaller sample studies (2.71; 95\% CI, 0.55-13.26); however, again there was no significant differences detected (Cochran $Q=0.01 ; \mathrm{P}=0.93$ ). There were also no significant differences in the OR of tuberculosis infection with infliximab therapy accompanied with or without immunosuppressor (2.96; 95\% CI, 0.94-9.29; and 2.59; 95\% CI, 0.42-15.92; respectively, Cochran $\mathrm{Q}=0.02, \mathrm{P}=0.90)$. When screening for tuberculosis prior to the examination of therapy according to the study design, the OR was also increased in trials that screened for tuberculosis $(3.10 ; 95 \%$ CI, 1.04-9.21), as compared with those without screening $(2.09$; 95\% CI, 0.26-17.13) (Cochran $\mathrm{Q}=0.11$, $\mathrm{P}=0.74$ ). Finally, risk of bias was judged in the RCTs (Fig. 3), the OR was elevated in trials with high or unclear risk (3.14; 95\% CI, 0.93-10.54), as compared with those at low risk (2.35; 95\% CI, 0.47-11.77); however, there was also no significant differences detected (Cochran $\mathrm{Q}=0.08 ; \mathrm{P}=0.78$ ). The results showed that subgroup differences did not increase the risk of tuberculosis infection with infliximab therapy compared with placebo.

Publication bias. Funnel plot analysis was performed, as demonstrated in Fig. 4. Funnel plot asymmetry was detected in the present meta-analysis (Egger test, $\mathrm{P}=0.002$ and Begger test, $\mathrm{P}=0.004)$. These results provide some evidence of publication bias in the present study.

\section{Discussion}

TNF- $\alpha$ is required for granuloma formation and maintenance, and has an important role in host defense against diseases caused by intracellular pathogens, such as Mycobacterium tuberculosis, Histoplasma capsulatum and Listeria monocytogenes (48-50). The increased clinical use of TNF- $\alpha$ antagonists has markedly improved the management of immunomediated diseases; however, it may have led to an increase in the incidence of infections with intracellular agents. To the best of our knowledge, the present meta-analysis was the first to evaluate the potential risk of tuberculosis infection with infliximab therapy in the management of RA, SpA and IBD, by collating all obtainable data from 24 individual RCTs. The present meta-analysis demonstrated that the OR of tuberculosis infection with infliximab therapy was 2.86-fold greater than when using the placebo. However, the ORs in all three disease subgroups were not demonstrated to be statistically significant.

The role of TNF- $\alpha$ in the human immune response to M. tuberculosis is yet to be fully elucidated. An in vitro study has proposed that TNF- $\alpha$ has a significant role in the regulation of granuloma formation, which limits microbial growth (51). TNF- $\alpha$, which is a pleiotropic cytokine produced by infected and activated macrophages/proinflammatory $\mathrm{T}$ cells, enhances 


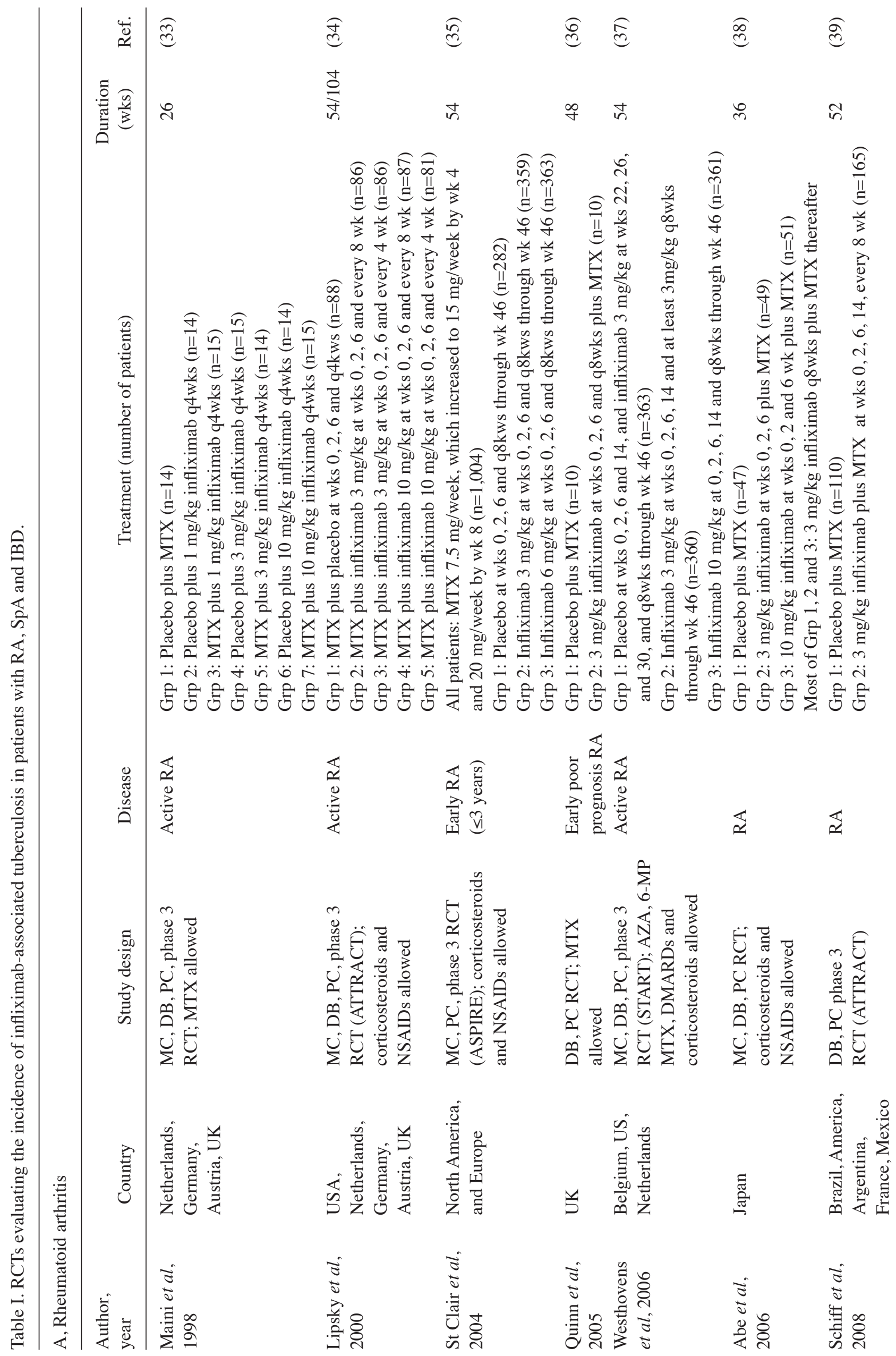




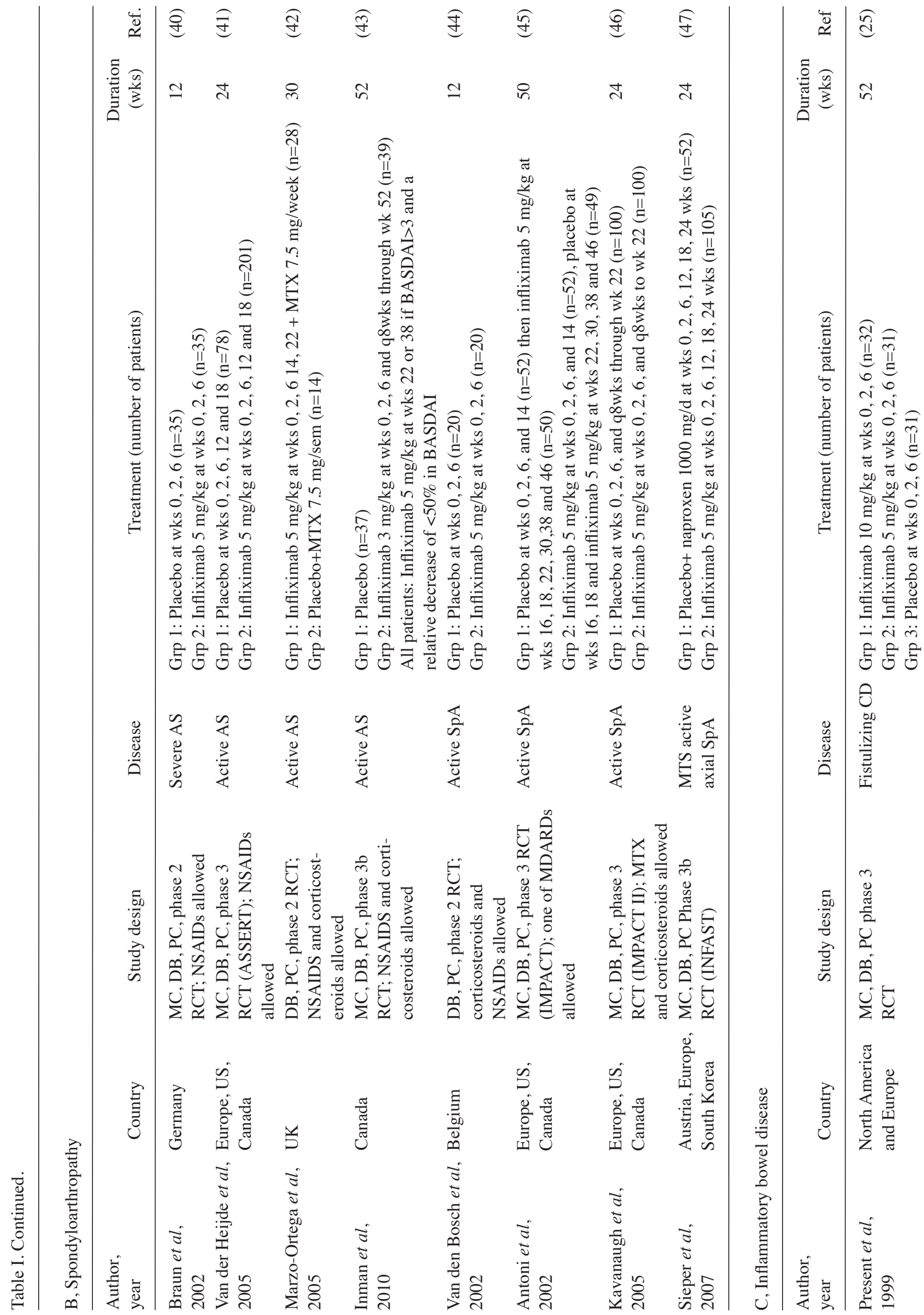




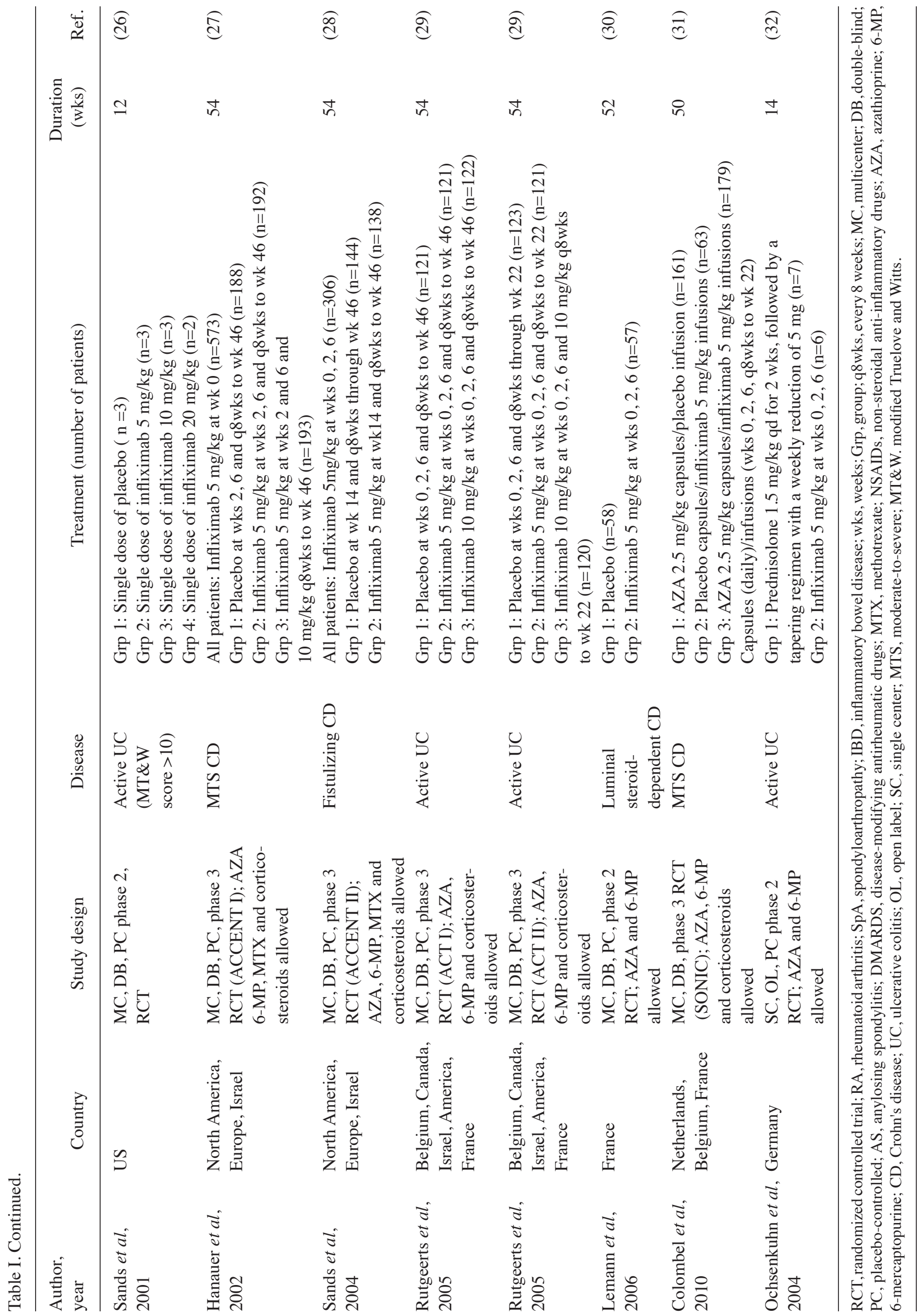




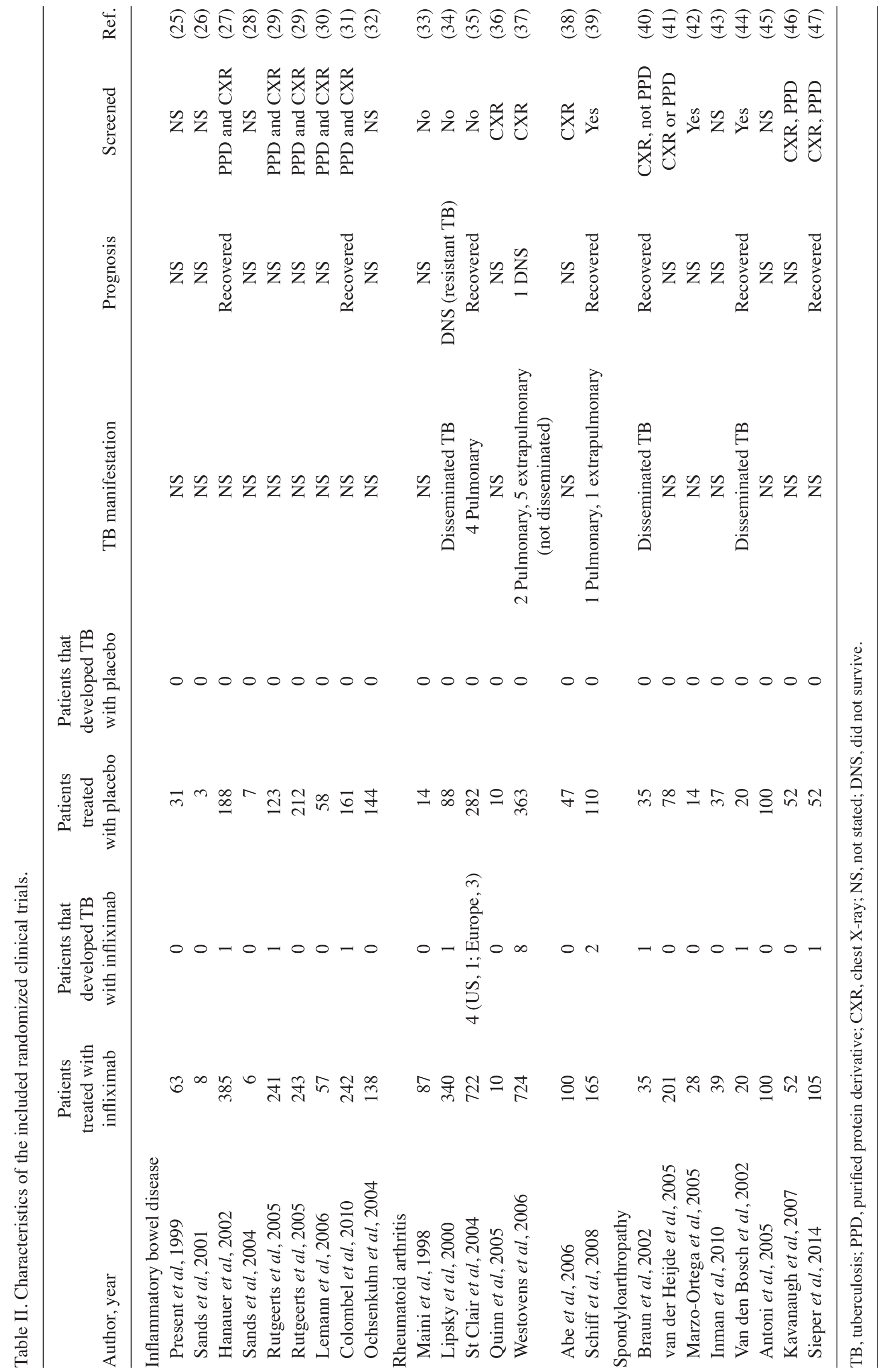


Table III. Rates of tuberculosis infection following infliximab therapy versus placebo in patients with RA, IBD and SpA.

\begin{tabular}{|c|c|c|c|c|c|}
\hline Disease & $\begin{array}{l}\text { Number } \\
\text { of trials }\end{array}$ & $\begin{array}{l}\text { Total number of } \\
\text { infliximab patients }\end{array}$ & $\begin{array}{c}\text { Number of infliximab } \\
\text { patients infected with } \\
\text { tuberculosis }(\%)\end{array}$ & $\begin{array}{l}\text { Total number of } \\
\text { placebo patients }\end{array}$ & $\begin{array}{l}\text { Number of placebo } \\
\text { patients infected with } \\
\text { tuberculosis }(\%)\end{array}$ \\
\hline RA & 7 & 2,148 & $15(0.70)$ & 914 & $0(0)$ \\
\hline IBD & 8 & 580 & $3(0.52)$ & 388 & $0(0)$ \\
\hline $\mathrm{SpA}$ & 9 & 1,383 & $3(0.22)$ & 927 & $0(0)$ \\
\hline Total & 24 & 4,111 & $21(0.51)$ & 2,229 & $0(0)$ \\
\hline
\end{tabular}

RA, rheumatoid arthritis; IBD, inflammatory bowel disease; SpA, spondyloarthropathy.

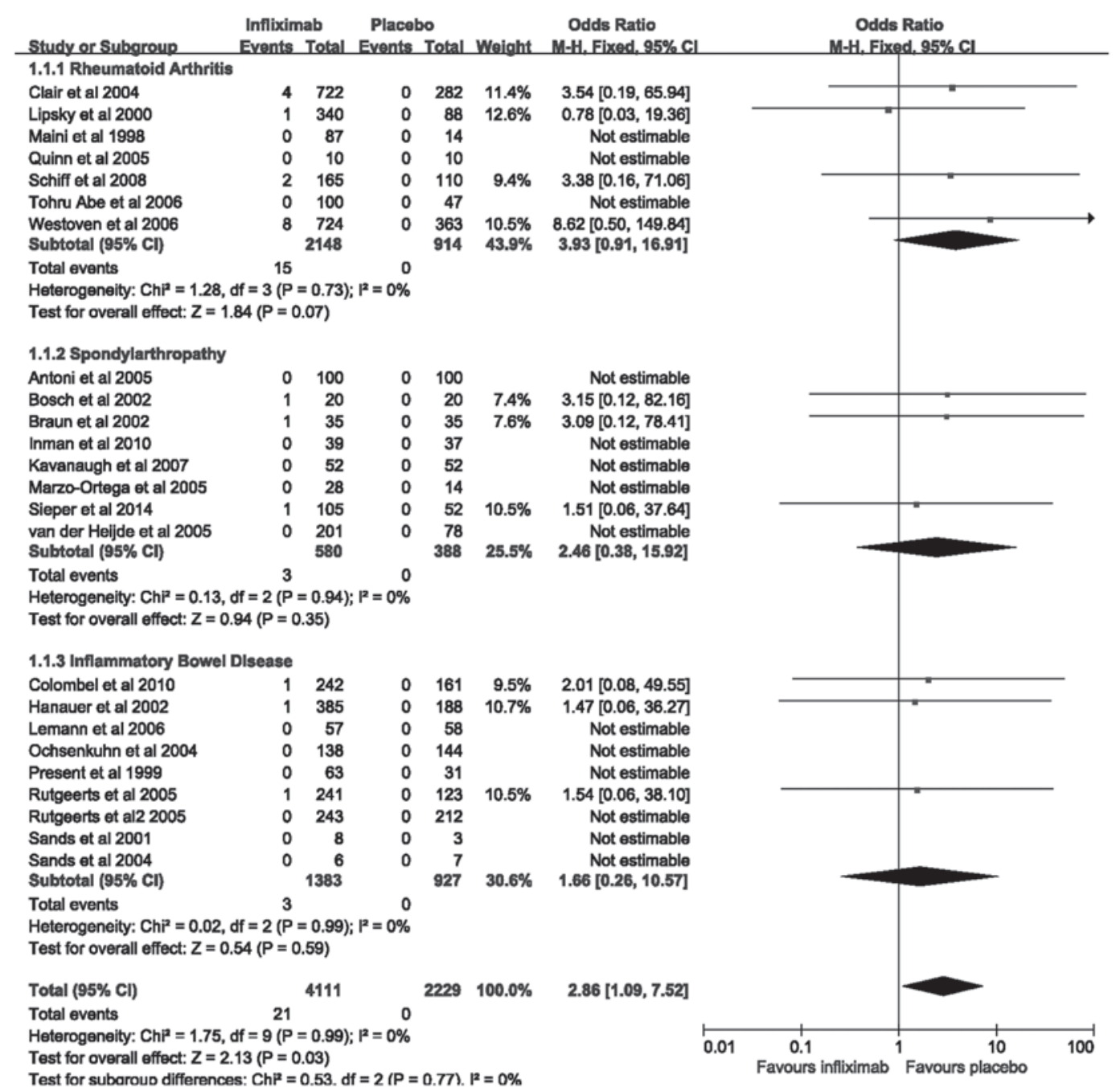

Figure 2. Forest plot of tuberculosis infection in randomized controlled trials of infliximab therapy vs. placebo in rheumatoid arthritis, spondyloarthropathy and inflammatory bowel disease. M-H, Mantel-Haenszel; CI, confidence interval.

macrophage activation, chemokine production by macrophages, and immune cell recruitment during tuberculosis infection (51). Anti-TNF- $\alpha$ monoclonal antibody administration may subsequently increase the risk of the dissolution of intact granulomas, the production of viable mycobacteria, and disease reactivation. This may clarify the increased likelihood of tuberculosis that was observed in patients receiving infliximab therapy.
In the present meta-analysis, 21 cases of tuberculosis, including 15 patients with RA, 3 patients with SpA and 3 patients with IBD, were evaluated. There were some limitations to the present study, even though the probability in each disease subgroup was not statistically significant. Firstly, as a consequence of latent tuberculosis infection (LTBI) screening, a relatively low number of cases of TB activation were recorded in clinical trials of infliximab in IBD, RA and 
Table IV. Subgroup analyses of the odds ratio of TB infection with infliximab therapy vs. placebo in IBD, RA and SpA.

\begin{tabular}{|c|c|c|c|c|c|c|}
\hline Variable & $\begin{array}{l}\text { Number of } \\
\text { trials }\end{array}$ & $\begin{array}{c}\text { Number of } \\
\text { infliximab patients }\end{array}$ & $\begin{array}{c}\text { Number of } \\
\text { placebo patients }\end{array}$ & $\begin{array}{c}\text { OR of } \\
\text { TB infection }\end{array}$ & $95 \% \mathrm{CI}$ & $\begin{array}{l}I^{2} \text { value } \\
(\%)\end{array}$ \\
\hline All trials & 24 & 4,111 & 2,229 & 2.86 & $1.09-7.52$ & 0 \\
\hline \multicolumn{7}{|l|}{ Disease } \\
\hline RA & 7 & 2,148 & 914 & 3.93 & $0.91-16.91$ & 0 \\
\hline SpA & 8 & 580 & 388 & 2.46 & $0.38-15.92$ & 0 \\
\hline IBD & 9 & 1,383 & 927 & 1.66 & $0.26-10.57$ & 0 \\
\hline \multicolumn{7}{|c|}{ Duration of therapy } \\
\hline$\geq 50$ weeks & 13 & 3,327 & 1,760 & 3.00 & $0.97-9.29$ & 0 \\
\hline$<50$ weeks & 11 & 784 & 469 & 2.46 & $0.38-15.92$ & 0 \\
\hline \multicolumn{7}{|c|}{ Immunosuppressor use } \\
\hline Yes & 17 & 3,390 & 1,771 & 2.96 & $0.94-9.29$ & 0 \\
\hline No & 7 & 721 & 458 & 2.59 & $0.42-15.92$ & 0 \\
\hline \multicolumn{7}{|l|}{ Screened for TB } \\
\hline Yes & 16 & 2,556 & 1,471 & 3.10 & $1.04-9.21$ & 0 \\
\hline No & 5 & 1,149 & 384 & 2.09 & $0.26-17.13$ & 0 \\
\hline \multicolumn{7}{|l|}{ Sample size ${ }^{a}$} \\
\hline Large & 8 & 3,098 & 1,495 & 2.94 & $0.87-9.94$ & 0 \\
\hline Small & 16 & 1,013 & 734 & 2.71 & $0.55-13.26$ & 0 \\
\hline \multicolumn{7}{|l|}{ Risk of bias } \\
\hline Low risk & 7 & 896 & 579 & 2.35 & $0.47-11.77$ & 0 \\
\hline High or unclear & 17 & 3,215 & 1,650 & 3.14 & $0.93-10.54$ & 0 \\
\hline
\end{tabular}

${ }^{2}$ Large samples sizes were $\geq 200$ participants, whereas small sample sizes were $<200$ participants. TB, tuberculosis; RA, rheumatoid arthritis; IBD, inflammatory bowel disease; SpA, spondyloarthropathy; OR, odds ratio; CI, confidence interval.
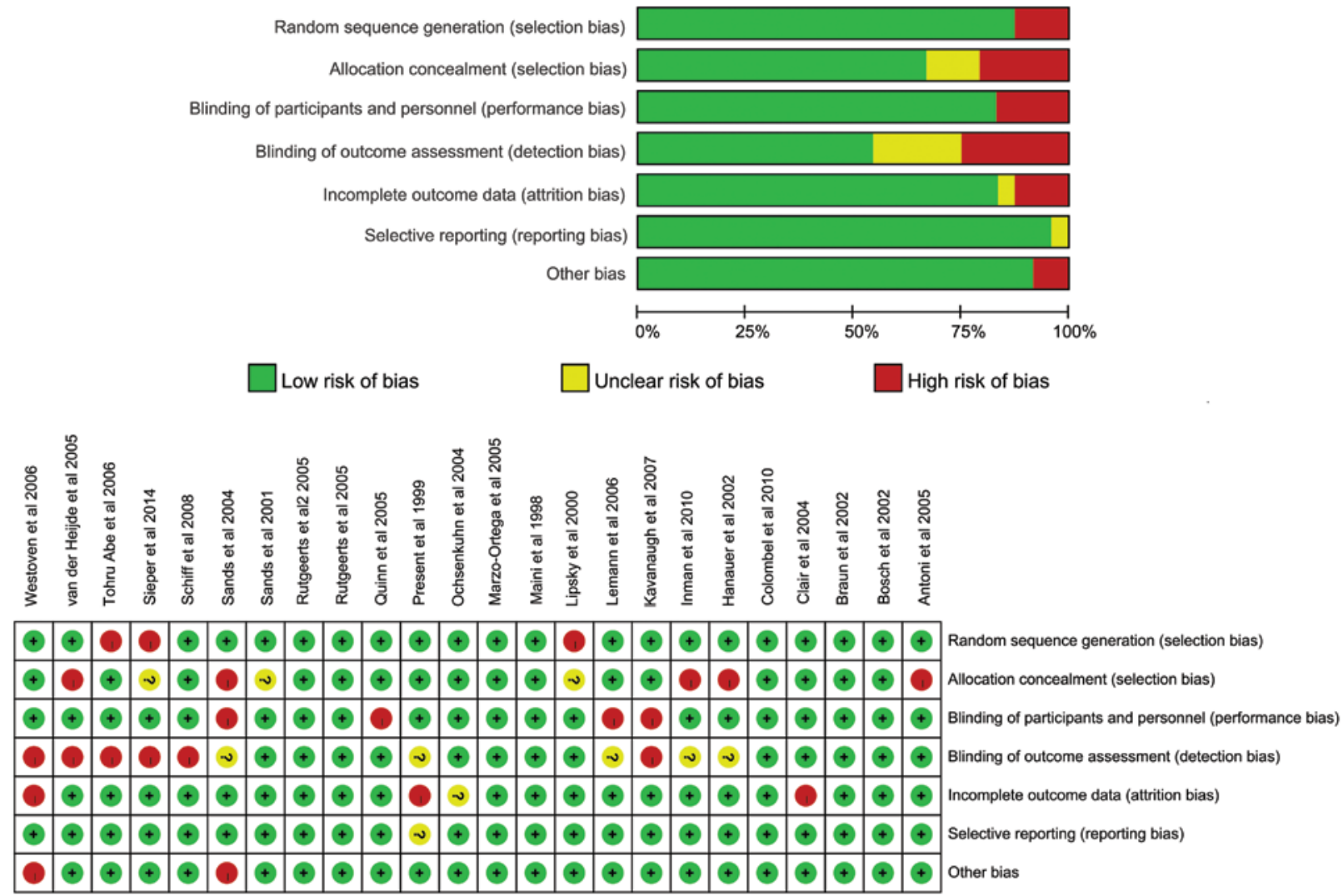

Figure 3. Risk of bias in 24 randomized controlled trials of tuberculosis infection with infliximab therapy. 


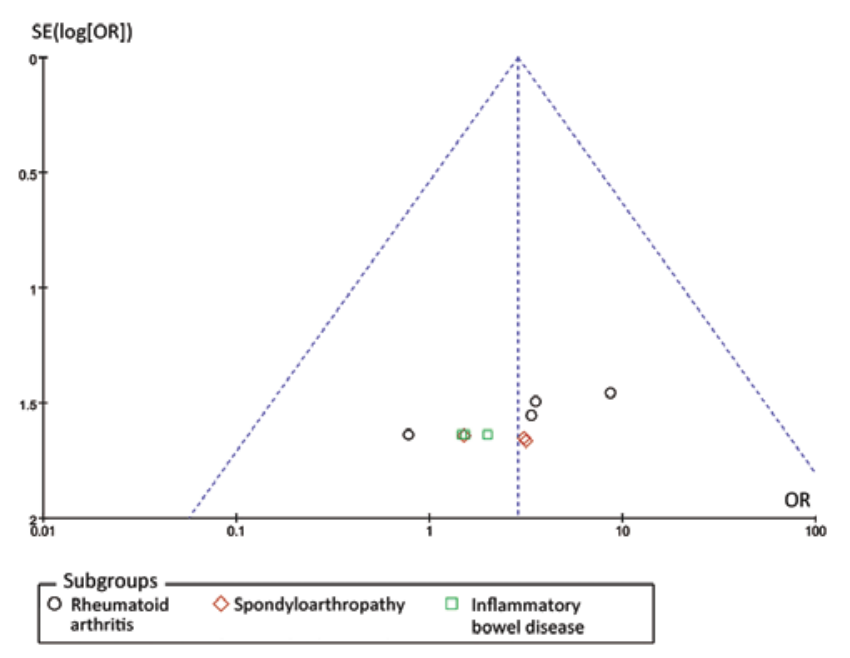

Figure 4. Funnel plot of studies that evaluated the association between infliximab therapy and the risk of tuberculosis infection, vs. placebo.

SpA. Overall, there were $0.51 \%$ cases of tuberculosis, $0.70 \%$ of which were in patients with RA, and 0.52 and $0.22 \%$ cases were in those with IBD and SpA, respectively. Compared with the tuberculosis incidence $(38-300 / 100,000)$ in the general population based on data from the WHO in 2013, infliximab infusion appears to increase the occurrence of tuberculosis (52). However, a major limitation of the present meta-analysis is that there were only 21 tuberculosis cases included; thus the small sample size may account for why the ORs for the risk of infliximab-associated tuberculosis were consistently demonstrated to lack significance in IBD, RA and SpA. Therefore, the results of the present meta-analysis should be interpreted with caution. Secondly, besides a single trial performed in Japan, the remaining studies were conducted in Europe and the USA, with apparent variations in tuberculosis risk among the different countries. Due to the low incidence of tuberculosis in the Western countries, the incidence of tuberculosis infection in patients treated with inflaximab may be underestimated. Thirdly, the majority of tuberculosis cases were in RA trials, suggesting that the underlying disease and previous immunosuppressive treatment may constitute adjunctive risk factors for tuberculosis activation. Indeed, patients with SpA and IBD predominantly have limited background of immunosuppressive therapies when compared with sufferers of RA. However, not all trials included in the present study constrained the immunosuppressive therapies prior to enrollment, which may have impacted the precision of assessing the risk of infliximab therapy without or with immunosuppressors. The screening procedure for LTBI was reported in 14 trials, whereas it was not documented in the others. Conversely, despite the elevated risk that was demonstrated in the trials after the introduction of procedures to identify LTBI, screening procedures for LTBI prior to treatment are still required due to the limited sample size, relatively low incidence of tuberculosis infection and publication bias. For that reason, screening and management for latent tuberculosis is essential prior to the administration of anti-TNF- $\alpha$ treatments.

It has been demonstrated that infliximab infusion raises the tuberculosis incidence rate $(35,38,39)$. The incidence rate of tuberculosis within this critique may be an underestimation, as the majority of the data that was analyzed originated from Western countries, whereas tuberculosis infection has a higher prevalence in developing countries. As is the situation in China, with the evolution of diagnostic techniques and medical treatment, RA, SpA and IBD incidence increased due to an increase in diagnosis. Despite the cost of infliximab, some patients are able to afford the cost and they are now at an increased risk for tuberculosis infection with a high latent infection rate among the population. It may be interesting to undertake multi-center clinical trials in East Asia in order to avoid inclusion bias.

By comparison, a significant proportion of extra-pulmonary and disseminated forms of tuberculosis were recognized, regardless of the preceding latent tuberculosis screening and treatment $(38,39)$. The frame from the initial infusion to the incidence of tuberculosis varies and no obvious dose dependent effect was observed. These findings suggest that merely screening for TB and treating it prior to infliximab is not sufficient. Additional follow-up is required in order to carefully assess the potential of extra-pulmonary tuberculosis occurring at any dosage, months or years after infusion. The present meta-analysis established that infliximab therapy induced tuberculosis. This indicated that the overall likelihood of TB infection in patients receiving infliximab infusion is sufficient to justify the overall screening, prophylaxis treatment, and close observation of this potentially fatal side effect. Therefore, we consider a PPD test or tuberculin skin test and chest X-ray to be essential prior to treatment, particularly in developing countries.

The present research exhibited numerous positive aspects. Firstly, demanding and conventional methodologies were applied to conduct the present meta-analysis, including the reporting of our search strategy, inclusion criteria, and data extraction process. Moreover, data extraction was conducted by two independent reviewers. Secondly, all trials enrolled in the meta-analysis were high quality RCTs. Finally, no significant heterogeneity was detected between the studies when data were pooled to estimate the OR of tuberculosis infection with infliximab therapy vs. placebo.

The present meta-analysis has several limitations, as a result of the qualities of the published literature that is readily available for analysis. Firstly, only seven of the RCTs were at a low risk of bias, and the quantity of subjects incorporated into the present meta-analysis was limited. Secondly, with the exception of one RCT, all included trials were from developed countries with low tuberculosis incidence rates, and studies from developing countries with a high incidence of tuberculosis were not available, which resulted in a publication bias. Finally, other concerns regarding potential biases remain. In particular, the included trials did not provide any information regarding host-related risk factors, including ethnicity, malnutrition, drug abuse, comorbidity, and contact with infected persons.

In conclusion, the present meta-analysis of 24 RCTs, comprising details from $>6,340$ patients with RA, SpA and IBD, demonstrated that the OR of tuberculosis infection was markedly increased with infliximab therapy, as compared with placebo therapy. The overall rates of tuberculosis infection were low $(0.51 \%)$. 


\section{Acknowledgements}

The present study was supported by Zhejiang Provincial Traditional Chinese Medicine Science Research Foundation (grant no. 2015ZA010) and Zhejiang Provincial Medical and Health science Foundation (grant no. 2015KYB020).

\section{References}

1. Knight DM, Trinh H, Le J, Siegel S, Shealy D, McDonough M, Scallon B, Moore MA, Vilcek J, Daddona P, et al: Construction and initial characterization of a mouse-human chimeric anti-TNF antibody. Mol Immunol 30: 1443-1453, 1993.

2. Scallon BJ, Moore MA, Trinh H, Knight DM and Ghrayeb J: Chimeric anti-TNF-alpha monoclonal antibody cA2 binds recombinant transmembrane TNF-alpha and activates immune effector functions. Cytokine 7: 251-259, 1995.

3. Van Deventer SJ: Tumour necrosis factor and Crohn's disease. Gut 40: 443-448, 1997.

4. Feldmann M, Brennan FM and Maini RN: Rheumatoid arthritis. Cell 85: 307-310, 1996.

5. Guignard S, Gossec L, Salliot C, Ruyssen-Witrand A, Luc M, Duclos M and Dougados M: Efficacy of tumour necrosis factor blockers in reducing uveitis flares in patients with spondylarthropathy: A retrospective study. Ann Rheum Dis 65 1631-1634, 2006.

6. Murch SH, Braegger CP, Walker-Smith JA and MacDonald TT: Location of tumour necrosis factor alpha by immunohistochemistry in chronic inflammatory bowel disease. Gut 34: 1705-1709, 1993.

7. Husby G and Williams RC Jr: Synovial localization of tumor necrosis factor in patients with rheumatoid arthritis. J Autoimmun 1: 363-371, 1988.

8. Tse SM, Burgos-Vargas R and Laxer RM: Anti-tumor necrosis factor alpha blockade in the treatment of juvenile spondylarthropathy. Arthritis Rheum 52: 2103-2108, 2005.

9. Aaltonen KJ, Virkki LM, Malmivaara A, Konttinen YT, Nordström DC and Blom M: Systematic review and meta-analysis of the efficacy and safety of existing TNF blocking agents in treatment of rheumatoid arthritis. PLoS One 7: e30275, 2012.

10. Wiens A, Correr CJ, Venson R, Grochocki MC, Otuki MF and Pontarolo R: A meta-analysis of the efficacy and safety of using infliximab for the treatment of rheumatoid arthritis. Clin Rheumatol 28: 1365-1373, 2009.

11. Wiens A, Venson R, Correr CJ, Otuki MF and Pontarolo R: Meta-analysis of the efficacy and safety of adalimumab, etanercept and infliximab for the treatment of rheumatoid arthritis Pharmacotherapy 30: 339-353, 2010.

12. Stidham RW, Lee TC, Higgins PD, Deshpande AR, Sussman DA, Singal AG, Elmunzer BJ, Saini SD, Vijan S and Waljee AK: Systematic review with network meta-analysis: The efficacy of anti-tumour necrosis factor-alpha agents for the treatment of ulcerative colitis. Aliment Pharmacol Ther 39: 660-671, 2014.

13. Scheinfeld N: A comprehensive review and evaluation of the side effects of the tumor necrosis factor alpha blockers etanercept, infliximab and adalimumab. J Dermatolog Treat 15: 280-294, 2004.

14. Flynn JL, Goldstein MM, Chan J, Triebold KJ, Pfeffer K, Lowenstein CJ, Schreiber R, Mak TW and Bloom BR: Tumor necrosis factor-alpha is required in the protective immune response against Mycobacterium tuberculosis in mice. Immunity 2: 561-572, 1995

15. Kindler V, Sappino AP, Grau GE, Piguet PF and Vassalli P: The inducing role of tumor necrosis factor in the development of bactericidal granulomas during BCG infection. Cell 56: 731-740, 1989.

16. Mohan VP, Scanga CA, Yu K, Scott HM, Tanaka KE, Tsang E, Tsai MM, Flynn JL and Chan J: Effects of tumor necrosis factor alpha on host immune response in chronic persistent tuberculosis: Possible role for limiting pathology. Infect Immun 69: $1847-1855,2001$.

17. Ford AC and Peyrin-Biroulet L: Opportunistic infections with anti-tumor necrosis factor-alpha therapy in inflammatory bowel disease: Meta-analysis of randomized controlled trials. Am J Gastroenterol 108: 1268-1276, 2013.

18. Keane J, Gershon S, Wise RP, Mirabile-Levens E, Kasznica J, Schwieterman WD, Siegel JN and Braun MM: Tuberculosis associated with infliximab, a tumor necrosis factor alpha-neutralizing agent. N Engl J Med 345: 1098-1104, 2001.
19. Wallis RS, Broder MS, Wong JY, Hanson ME and Beenhouwer DO: Granulomatous infectious diseases associated with tumor necrosis factor antagonists. Clin Infect Dis 38: 1261-1265, 2004

20. Askling J, Fored CM, Brandt L, Baecklund E, Bertilsson L, Cöster L, Geborek P, Jacobsson LT, Lindblad S, Lysholm J, et al: Risk and case characteristics of tuberculosis in rheumatoid arthritis associated with tumor necrosis factor antagonists in Sweden. Arthritis Rheum 52: 1986-1992, 2005.

21. Moher D, Liberati A, Tetzlaff J and Altman DG; PRISMA Group: Preferred reporting items for systematic reviews and meta-analyses: The PRISMA statement. PLoS Med 6: e1000097, 2009.

22. Jadad AR, Moore RA, Carroll D, Jenkinson C, Reynolds DJ, Gavaghan DJ and McQuay HJ: Assessing the quality of reports of randomized clinical trials: Is blinding necessary? Control Clin Trials 17: 1-12, 1996.

23. Moher D, Pham B, Jones A, Cook DJ, Jadad AR, Moher M, Tugwell P and Klassen TP: Does quality of reports of randomised trials affect estimates of intervention efficacy reported in meta-analyses? Lancet 352: 609-613, 1998.

24. Targan SR, Hanauer SB, van Deventer SJ, Mayer L, Present DH, Braakman T, DeWoody KL, Schaible TF and Rutgeerts PJ: A short-term study of chimeric monoclonal antibody cA2 to tumor necrosis factor alpha for Crohn's disease. Crohn's Disease cA2 Study Group. N Engl J Med 337: 1029-1035, 1997.

25. Present DH, Rutgeerts P, Targan S, Hanauer SB, Mayer L, van Hogezand RA, Podolsky DK, Sands BE, Braakman T, DeWoody KL, et al: Infliximab for the treatment of fistulas in patients with Crohn's disease. N Engl J Med 340: 1398-1405, 1999.

26. Sands BE, Tremaine WJ, Sandborn WJ, Rutgeerts PJ, Hanauer SB, Mayer L, Targan SR and Podolsky DK: Infliximab in the treatment of severe, steroid-refractory ulcerative colitis: A pilot study. Inflamm Bowel Dis 7: 83-88, 2001.

27. Hanauer SB, Feagan BG, Lichtenstein GR, Mayer LF, Schreiber S, Colombel JF, Rachmilewitz D, Wolf DC, Olson A, Bao W, et al; ACCENT I Study Group: Maintenance infliximab for Crohn's disease: The ACCENT I randomised trial. Lancet 359: 1541-1549, 2002.

28. Sands BE, Anderson FH, Bernstein CN, Chey WY, Feagan BG, Fedorak RN, Kamm MA, Korzenik JR, Lashner BA, Onken JE, et al: Infliximab maintenance therapy for fistulizing Crohn's disease. N Engl J Med 350: 876-885, 2004.

29. Rutgeerts P, Sandborn WJ, Feagan BG, Reinisch W, Olson A, Johanns J, Travers S, Rachmilewitz D, Hanauer SB, Lichtenstein GR, et al: Infliximab for induction and maintenance therapy for ulcerative colitis. N Engl J Med 353: 2462-2476, 2005.

30. Lemann M, Mary JY, Duclos B, Veyrac M, Dupas JL, Delchier JC, Laharie D, Moreau J, Cadiot G, Picon L, et al: Infliximab plus azathioprine for steroid-dependent Crohn's disease patients: A randomized placebo-controlled trial. Gastroenterology 130: 1054-1061, 2006.

31. Colombel JF, Sandborn WJ, Reinisch W, Mantzaris GJ, Kornbluth A, Rachmilewitz D, Lichtiger S, D'Haens G, Diamond RH, Broussard DL, et al: Infliximab, azathioprine, or combination therapy for Crohn's disease. N Engl J Med 362: 1383-1395, 2010

32. Ochsenkuhn T, Sackmann M and Göke B: Infliximab for acute, not steroid-refractory ulcerative colitis: A randomized pilot study. Eur J Gastroenterol Hepatol 16: 1167-1171, 2004.

33. Maini RN, Breedveld FC, Kalden JR, Smolen JS, Davis D, Macfarlane JD, Antoni C, Leeb B, Elliott MJ, Woody JN, et al: Therapeutic efficacy of multiple intravenous infusions of anti-tumor necrosis factor alpha monoclonal antibody combined with low-dose weekly methotrexate in rheumatoid arthritis. Arthritis Rheum 41: 1552-1563, 1998.

34. Lipsky PE, van der Heijde DM, St Clair EW, Furst DE, Breedveld FC, Kalden JR, Smolen JS, Weisman M, Emery P, Feldmann M, et al: Infliximab and methotrexate in the treatment of rheumatoid arthritis. Anti-tumor necrosis factor trial in rheumatoid arthritis with concomitant therapy study group. N Engl J Med 343: 1594-1602, 2000.

35. St Clair EW, van der Heijde DM, Smolen JS, Maini RN, Bathon JM, Emery P, Keystone E, Schiff M, Kalden JR, Wang B, et al; Active-Controlled Study of Patients Receiving Infliximab for the Treatment of Rheumatoid Arthritis of Early Onset Study Group: Combination of infliximab and methotrexate therapy for early rheumatoid arthritis: A randomized, controlled trial. Arthritis Rheum 50: 3432-3443, 2004 
36. Quinn MA, Conaghan PG, O'Connor PJ, Karim Z, Greenstein A, Brown A, Brown C, Fraser A, Jarret S and Emery P: Very early treatment with infliximab in addition to methotrexate in early, poor-prognosis rheumatoid arthritis reduces magnetic resonance imaging evidence of synovitis and damage, with sustained benefit after infliximab withdrawal: Results from a twelve-month randomized, double-blind, placebo-controlled trial. Arthritis Rheum 52: 27-35, 2005.

37. Westhovens R, Yocum D, Han J, Berman A, Strusberg I, Geusens P and Rahman MU; START Study Group: The safety of infliximab, combined with background treatments, among patients with rheumatoid arthritis and various comorbidities: A large, randomized, placebo-controlled trial. Arthritis Rheum 54: 1075-1086, 2006.

38. Abe T, Takeuchi T, Miyasaka N, Hashimoto H, KondoH,Ichikawa Y and Nagaya I: A multicenter, double-blind, randomized, placebo controlled trial of infliximab combined with low dose methotrexate in Japanese patients with rheumatoid arthritis. J Rheumatol 33 37-44, 2006.

39. Schiff M, Keiserman M, Codding C, Songcharoen S, Berman A, Nayiager S, Saldate C, Li T, Aranda R, Becker JC, et al: Efficacy and safety of abatacept or infliximab vs placebo in ATTEST: A phase III, multi-centre, randomised, double-blind, placebocontrolled study in patients with rheumatoid arthritis and an inadequate response to methotrexate. Ann Rheum Dis 67: 10961103,2008

40. Braun J, Brandt J, Listing J, Zink A, Alten R, Golder W, Gromnica-Ihle E, Kellner H, Krause A, Schneider M, et al: Treatment of active ankylosing spondylitis with infliximab: A randomised controlled multicentre trial. Lancet 359: 1187-1193, 2002.

41. van der Heijde D, Dijkmans B, Geusens P, Sieper J, DeWoody K, Williamson P and Braun J; Ankylosing Spondylitis Study for the Evaluation of Recombinant Infliximab Therapy Study Group: Efficacy and safety of infliximab in patients with ankylosing spondylitis: Results of a randomized, placebo-controlled trial (ASSERT). Arthritis Rheum 52: 582-591, 2005.

42. Marzo-Ortega H, McGonagle D, Jarrett S, Haugeberg G, Hensor E, O'connor P, Tan AL, Conaghan PG, Greenstein A and Emery P: Infliximab in combination with methotrexate in active ankylosing spondylitis: A clinical and imaging study. Ann Rheum Dis 64: 1568-1575, 2005.

43. Inman RD and Maksymowych WP; CANDLE Study Group: Adouble-blind, placebo-controlled trial of low dose infliximab in ankylosing spondylitis. J Rheumatol 37: 1203-1210, 2010.
44. Van den Bosch F, Kruithof E, Baeten D, Herssens A, de Keyser F, Mielants $\mathrm{H}$ and Veys EM: Randomized double-blind comparison of chimeric monoclonal antibody to tumor necrosis factor alpha (infliximab) versus placebo in active spondylarthropathy. Arthritis Rheum 46: 755-765, 2002.

45. Antoni C, Krueger GG, de Vlam K, Birbara C, Beutler A, Guzzo C, Zhou B, Dooley LT and Kavanaugh A; IMPACT 2 Trial Investigators: Infliximab improves signs and symptoms of psoriatic arthritis: Results of the IMPACT 2 trial. Ann Rheum Dis 64: 1150-1157, 2005.

46. Kavanaugh A, Krueger GG, Beutler A, Guzzo C, Zhou B, Dooley LT, Mease PJ, Gladman DD, de Vlam K, Geusens PP, et al: Infliximab maintains a high degree of clinical response in patients with active psoriatic arthritis through 1 year of treatment: Results from the IMPACT 2 trial. Ann Rheum Dis 66: 498-505, 2007.

47. Sieper J, Lenaerts J, Wollenhaupt J, Rudwaleit M, Mazurov VI, Myasoutova L, Park S, Song Y, Yao R, Chitkara D, et al: Efficacy and safety of infliximab plus naproxen vs. naproxen alone in patients with early, active axial spondyloarthritis: Results from the double-blind, placebo-controlled INFAST study, Part 1. Ann Rheum Dis 73: 101-107, 2014.

48. Algood HM, Lin PL and Flynn JL: Tumor necrosis factor and chemokine interactions in the formation and maintenance of granulomas in tuberculosis. Clin Infect Dis 41 (Suppl 3): S189-S193, 2005.

49. White DW and Harty JT: Perforin-deficient $\mathrm{CD}^{+} \mathrm{T}$ cells provide immunity to Listeria monocytogenes by a mechanism that is independent of CD95 and IFN-gamma but requires TNF-alpha. J Immunol 160: 898-905, 1998.

50. Zhou P, Miller G and Seder RA: Factors involved in regulating primary and secondary immunity to infection with Histoplasma capsulatum: TNF-alpha plays a critical role in maintaining secondary immunity in the absence of IFN-gamma. J Immunol 160: 1359-1368, 1998.

51. Roach DR, Bean AG, Demangel C, France MP, Briscoe H and Britton WJ: TNF regulates chemokine induction essential for cell recruitment, granuloma formation, and clearance of mycobacterial infection. J Immunol 168: 4620-4627, 2002.

52. Zumla A, George A, Sharma V, Herbert N and Baroness Masham of Ilton: WHO's 2013 global report on tuberculosis: Successes, threats, and opportunities. Lancet 382: 1765-1767, 2013. 